\title{
O fenômeno workaholic na gestão de empresas*
}

\author{
Maurício Serva** \\ Joel Lincoln Oliveira Ferreira***
}

S U MÁRIO: 1. Introdução; 2. Fundamentos teóricos; 3. Metodologia; 4. Análise dos dados; 5. Conclusões.

S um Mar Y : 1. Introduction; 2. Theoretical framework; 3. Method; 4. Data analysis; 5. Conclusions.

P AL A VRA S-CHA VE: exigências organizacionais; fenômeno workaholic; relação indivíduo-organização.

KEY WORDS: organizational demands; workaholic phenomenon; person-organization relation.

Este artigo levanta e estabelece as relações entre as exigências organizacionais sobre o gerente moderno e o fenômeno workaholic, identificando algumas implicações na vida dos indivíduos. $\mathrm{O}$ artigo analisa as relações de influências mútuas entre contextos, teorias organizacionais, exigências sobre os gerentes e fenômeno workaholic. O foco de estudo é o gerente, aquele que ocupa cargo de comando, toma decisões e tem certo grau de responsabilidade acumulada, em configuração relativamente ampla do cenário nacional, porquanto a pesquisa de natureza qualitativa foi feita com oito gerentes de empresas de segmentos e ramos diferentes, atuando em várias regiões do Brasil.

The workaholic phenomenon in business management

\footnotetext{
* Artigo recebido em dez. 2004 e aceito em set. 2005.

** Professor da PUC-PR. Presidente, no Brasil, do Centro Internacional de Pesquisa e Informação sobre a Economia Pública, Social e Cooperativa (Ciriec). Pós-doutorado em autonomia e gestão social na École des Hautes Études Commerciales de Montreal. Doutor e mestre em administração pela FGV-SP. Endereço: PUC-PR — Rua Imaculada Conceição, 1.155, Bloco acadêmico, 2ㅇandar — Prado Velho CEP 80215-901, Curitiba, PR, Brasil. E-mail: mserva@terra.com.br.

*** Professor das Faculdades Jorge Amado. Pesquisador do Centro Internacional de Pesquisa e Informação sobre a Economia Pública, Social e Cooperativa (Ciriec). Mestre em administração pela UFPR. Endereço: Av. Luis Vianna Filho, 6.775 - Paralela - CEP 41745-130, Salvador, BA, Brasil. E-mail: jolfs@hotmail.com.
} 
This article investigates and establishes the relationship between organizational demands on the modern manager and the workaholic phenomenon, identifying some implications on the life of the individual. It analyzes the relations of mutual influences within contexts, organizational theories, demands on the manager and the workaholic phenomenon. The focus is on the manager, the person who occupies the command position, makes decisions and has a certain degree of accumulated responsibilities, in a relatively broad configuration of the domestic scene, since the qualitative research was made with eight business managers, from different segments and sectors spread over Brazil.

\section{Introdução}

Para atender a uma realidade altamente competitiva de um mercado turbulento e descontínuo, as organizações cada vez mais estão atentas às características da natureza humana: anseios, aspirações, desejos, sonhos, ambições, entre outras e, com suas exigências organizacionais, buscam ter um trabalhador mais absorvido e integrado. As mudanças ambientais se acentuaram em tal velocidade que os acontecimentos e informações circulam online, fazendo com que o cotidiano dos indivíduos tomadores de decisão se torne ainda mais complexo. Uma dedicação integral e uma vida quase exclusivamente voltada para a empresa parecem ser a regra de sobrevivência nas organizações modernas e o caminho único de sucesso na carreira gerencial.

As exigências organizacionais feitas ao gerente, decorrentes da dinâmica das transformações no mundo moderno, parecem ter levado ao aumento da carga de trabalho e da quantidade de horas trabalhadas, bem como ao maior envolvimento com o trabalho e com a organização, seja para entender, seja para poder decidir, agir, responder às demandas diárias. Estar absorvido (física e psicologicamente) de forma integral pela organização em decorrência da complexidade, da diversidade e da dinâmica do mundo organizacional parece ser uma decorrência para o gerente. Uma pesquisa divulgada pela revista Exame (2002) e realizada pela Fundação Dom Cabral com 626 executivos brasileiros revelou que eles têm 71\% de seu tempo dedicado ao trabalho, e também que 66\% deles estão insatisfeitos com a divisão do tempo e da energia entre trabalho e vida pessoal.

Em outra pesquisa, feita pelo Grupo Catho (2003) com 223 empresários de todo o país em 2003, mostrou que $46 \%$ deles fazem refeições em até 20 minutos. O Instituto Datafolha divulgou uma pesquisa feita entre 4 e 25 de abril de 2003 sobre o perfil dos executivos na Região Metropolitana de São Paulo. A pesquisa, feita com 161 profissionais que ocupam cargo de liderança (gerentes, dirigentes e diretores) de empresas de grande, médio e pequeno portes selecionadas por região e ramo (para garantir a representatividade da amostra), mostra que mais de $50 \%$ desses profissionais têm jornada de trabalho de no mínimo 12 horas, e que 55\% têm reclamações 
da família por dedicar tempo insuficiente para o convívio. O estar absorvido de forma intensa com o trabalho, com longas jornadas diárias, excesso de carga de trabalho, ritmo acelerado de trabalhar e busca desenfreada por resultados, poderia talvez resultar em trabalhadores viciados em trabalho — workaholics —, o que parece ser uma deturpação na relação indivíduo-organização e um comprometimento da qualidade de vida do gerente, acarretando sérias conseqüiências para a saúde deles. Segundo dados divulgados pela seção brasileira da Internal Stress Management Association (Isma), em 2001 mais de $70 \%$ de 556 profissionais consultados sofriam de estresse. Esse índice mantém semelhança com o de outros países: 72\% dos gerentes nos EUA e 70\% na Inglaterra sofrem do mesmo problema (Valdejão, 2003).

Dados da NFI Research mostram que o estresse aumentou entre gerentes no mundo inteiro - pesquisa realizada em 50 países. O estudo mostra que o problema já atinge 79,3\% desses profissionais de forma intensa ou moderada (Lira, 2003). Outro estudo realizado pela Stanford University sobre estresse crônico teve como uma das conclusões da pesquisa que: "poucos executivos considerados bem-sucedidos, no conceito vigente, conseguem ter vida pessoal equilibrada” (Barros, 2002:376). As doenças já comprovadamente provocadas pelo estresse são inúmeras, de uma simples dor de cabeça até desencadeamento de diabetes, passando pelas doenças cardiovasculares, como arteriosclerose, angina pectoris, hipertensão, ataque cardíaco e outras, como gastrite, úlceras e distúrbios do sistema imunológico (Goldberg, 1980).

Todos esses estudos e pesquisas podem estar apontando para uma desarmonia na vida desses gerentes, tanto nos aspectos físicos e psicológicos, quanto também nos sociais. Para Killinger (1991), os workaholics são os "viciados respeitáveis” do nosso século e portanto não causa mais estranheza aos nossos olhos alguém que trabalhe 10, 12 ou 14 horas por dia. Assim sendo, as organizações parecem ser o "celeiro" desses viciados, chegando a ponto de alguns canais editoriais de popularização da administração elegerem o perfil do gerente de sucesso aquele que apresenta um ritmo acelerado de trabalho e resistência para agüentar o excesso de trabalho, o chamado “atleta-corporativo” (Exame, 2002). Este seria uma versão melhorada do workaholic, pois agora desvinculado da imagem pejorativa de um viciado em função de uma outra mais saudável: a de um atleta...

Nesse contexto, este artigo verifica se as exigências organizacionais atuais têm alguma relação com gerentes excessivamente absorvidos (física e mentalmente) com o seu trabalho, caracterizando dessa maneira um profissional viciado em trabalho - o workaholic. A perspectiva subjacente é a de que o fenômeno workaholic pode não se dever somente à predisposição psíquica de certos indivíduos. A estrutura do artigo é a seguinte: inicialmente, apresentaremos os fundamentos teóricos que embasam o artigo; na seqüência, esclareceremos a metodologia empregada no trabalho de campo e reportaremos a análise dos dados, chegando por fim às conclusões. 


\section{Fundamentos teóricos}

O fenômeno workaholic pode ser analisado sob diversos pontos de vista. Constatamos que a grande maioria dos estudos disponíveis sobre o fenômeno workaholic até então privilegiaram categorias de análise mais ligadas à psique do indivíduo, não focalizando com ênfase o contexto histórico nem o espaço social (as organizações) onde o fenômeno se manifesta. Apesar de reconhecer a importância desses estudos, optamos por realizar um estudo complementar, partindo do ponto de vista organizacional e levando em conta o contexto histórico no qual o fenômeno se manifesta com mais intensidade.

Como pano de fundo deste artigo, consideraremos o contexto histórico de 1975 aos dias atuais, marcado pela crise do fordismo. Esse é o período no qual o fenômeno workaholic ocorre com uma intensidade tal que acaba por despertar o interesse dos pesquisadores. Ao lado de uma breve caracterização desse período, reportaremos o papel do gerente e as exigências organizacionais correspondentes, como estabelecido pelas teorias administrativas contemporâneas. Na continuidade da apresentação dos fundamentos teóricos, faremos uma síntese de estudos sobre o tema em questão, para chegarmos a um rol de elementos de identificação do fenômeno workaholic, que utilizaremos na análise dos dados.

\section{O contexto: a crise do fordismo (1975 até o presente), o papel do gerente e as exigências organizacionais}

Atualmente, em diversas ciências sociais tais como a economia, a geografia, a sociologia e a ciência política, o termo fordismo transcende o significado comumente empregado na administração e refere-se a um conceito mais amplo, empregado para descrever o modelo geral de desenvolvimento adotado pelos países capitalistas industrializados a partir de 1945. O fordismo vinculava a remuneração dos trabalhadores aos ganhos de produtividade, permitindo assim um ganho real do poder aquisitivo do trabalhador e, conseqüen-temente, uma forma de se estimular o consumo em massa. Apoiado no tripé representado pelo progresso técnico-industrial, pelo progresso social entendido como o aumento do poder aquisitivo dos trabalhadores e pelos serviços prestados pelo Estado do bem-estar social, o fordismo garantiu um crescimento acelerado das economias dos países centrais durante 30 anos. Esse modelo de desenvolvimento entra em crise na década de 1970. Entre outros fatores, podemos aqui indicar alguns dos mais importantes no processo de decomposição do fordismo: a globalização da economia, tornando praticamente impossíveis a manutenção do regime de acumulação (aumento de salários vinculado ao aumento da produtividade) e o modo de regulação praticado pelos governos; a liberalização dos fluxos financeiros, expandindo sem limites o capital especulativo; o desemprego es- 
trutural crescente, aumentando as despesas do Estado; a crise ecológica, colocando limites ambientais ao crescimento industrial; a competitividade crescente dos países da Europa e do Japão, desequilibrando a regulação internacional comandada pelos EUA.

Assim, a crise do fordismo guarda profundas conexões com a explosão da competição empresarial em escala planetária, num cenário de uma economia internacional cada vez mais sujeita a abalos e sobressaltos graves. As organizações, evidentemente, não poderiam ficar imunes a tais mudanças espetaculares do contexto. Novas teorias administrativas são então elaboradas, ensejando novas formas de gerenciamento e portanto modificando o papel do gerente. O que faz o gerente? Assim começa Mintzberg (1973) o seu mais célebre livro, fruto de sua tese de doutorado e escrito no alvorecer da crise do fordismo. A partir dos registros de suas observações de campo, o autor formulou um conjunto dos principais papéis (interpessoais, informacionais e decisórios), subdivididos em 10 papéis secundários referentes ao tempo gasto do gerente no seu dia-a-dia. A síntese desses papéis nega que o trabalho do gerente, no contexto da crise, seja ordenado, contínuo, seqüencial, homogêneo, além de não ser derivado de suas próprias iniciativas nem de sua vontade transformada em decisões. John Kotter, professor na Universidade de Harvard, também chegou a conclusões semelhantes ao investigar, cuidadosamente, o dia de trabalho dos gerentes “bem-sucedidos”, conforme registrou Kliksberg (1993). O estudo de Motta (1991) apresenta resultados semelhantes às observações de Mintzberg. Ele identificou uma realidade de trabalho extremamente ambígua e repleta de dualidades, cuja ação gerencial se faz de forma fragmentada, intermitente, de natureza variável, reativa. Pelas informações levantadas por esses autores, percebe-se o exercício de uma função numa situação de quase caos (fragmentado, irregular, mitigado e variado), o controle de situação tão almejado apresenta-se utópico (extremamente mutável, descontínuo e de natureza variada), a previsibilidade e o planejamento rigoroso próximos ao que se poderia chamar de impossível (é uma série interrompida de reações, não é derivada de suas iniciativas e de sua vontade, a atenção volta-se apenas para o imediato).

Trataremos, em seguida, de algumas das exigências atuais ao gerente que freqüentemente são apontadas na literatura administrativa.

Aceitação ao risco. O papel do gerente requer, por definição, a aceitação de riscos de alguma espécie (McClelland, 1972, 1987; Ansoff, 1981; Sennett, 2000). Ampliando o fator risco para o contexto além organização — para a sociedade como um todo —, o sociólogo Ulrich Beck (1998) declara: "na modernidade avançada, a produção social de riqueza é sistematicamente acompanhada pelas produções sociais de riscos”. Se o elemento risco sempre existiu, o que o diferencia do passado é a sua contínua freqüência e a pretensão de apresentar-se como normal na sociedade 
moderna, além de se verificar como parte das exigências organizacionais aos gerentes o saber aceitar e lidar diariamente com este elemento.

Complexidade. Para Motta (1991:35), “a complexidade do mundo organizacional moderno tem modificado dimensões clássicas de gestão e substituído formas antes rígidas e precisas por formas ambíguas e flexíveis”. Questões como estrutura, hierarquia, especialização do trabalhador, formas de decisões administrativas adquirem características de flexibilidade em decorrência da complexidade. São alterações provocadas pela própria evolução do meio social, econômico e político em que estão inseridas as organizações. No cenário organizacional, há uma expectativa sobre gerentes que sejam capazes de gerir na complexidade do ambiente organizacional, operando em situações de instabilidade e imprevisibilidade, principalmente valorizando o trabalho em equipe para que possam chegar às mais razoáveis opções, abrindo mão da quase utópica melhor solução: “O novo gerente deve capitalizar as outras opiniões, porque é possível entender melhor a realidade complexa e ambígua, se os ângulos de leitura forem aumentados” (Kliksberg, 1993:195). Além do que, segundo análise de Motta (1991), a complexidade exige uma capacidade de diferenciação que ultrapassa os limites das associações simplistas, típicas do senso comum. Em verdade, a complexidade da empresa moderna carrega uma alta dose de contradições, paradoxos, desordens e irracionalidades. A atual taxa de inovação tecnológica é a mais alta e acelerada que se conhece na história da humanidade, e a baixa previsibilidade como característica central das grandes mudanças (Kliksberg, 1993) torna ainda mais complexo o trabalho de quem diariamente tem que se posicionar diante do novo, fazer escolhas, se inteirar e interagir com um ambiente externo globalmente integrado. Assim, o ambiente é não somente integrado, mas extremamente mutável, ambíguo e instável (Ansoff, 1981). Para Kliksberg (1993), o grande desafio da gerência é o de aprender a gerenciar a complexidade, sair das condições de estabilidade limitada e enfrentar meios em contínua mudança.

Flexibilidade. A complexidade exige flexibilidade e grande capacidade de ação por exceção. No trabalho do gerente moderno, não se apresenta mais como possível o controle ou o conhecimento do todo, a resposta em forma de ação vem por uma escolha ou decisão pelo controle da exceção. A complexidade também recai na flexibilidade devido às condições altamente mutantes, exigindo uma alta capacidade de adaptação. Para Motta (1991), a busca de flexibilidade pela administração se deu a partir de constatações crescentes de que as antigas formas organizacionais em que a estrutura antecedia outras dimensões da organização não mais se coadunavam com as necessidades atuais das empresas. Na análise de Sennett (2000) sobre as conseqüências da flexibilidade para os trabalhadores modernos, são apontadas ansiedade e angústia para os gerentes, uma vez que os riscos permanentes (carreira instável, metas a serem alcançadas, novidades constantes que podem mudar o rumo das de- 
cisões, instabilidade do capital “nervoso”...) não vêm acompanhados de garantia de que serão compensados; em outras palavras, a natureza do risco significa dúvida quanto ao seu resultado final. A flexibilidade para lidar com a instabilidade e a convivência com o fator risco requerem novas habilidades e competências do gerente, a fim de que essa nova situação nas organizações modernas não implique um estado de insegurança para ele, trazendo-lhe desequilíbrio psicológico e emocional. Sennett (2000) observa que as práticas administrativas modernas consistem em mudanças radicais que reinventam decisiva e irrevogavelmente as instituições; o exemplo citado é o da reengenharia, a estratégia da moda na década de 1990. A especialização combinada à flexibilidade é a antítese do sistema de produção do fordismo. Ela acontece graças aos softwares cada vez mais sofisticados que permitem reprogramar e configurar as máquinas industriais, de acordo com a demanda (volátil) de seus consumidores e a rapidez das comunicações.

Curto prazo. Ross Webber (1997) registra essa exigência das organizações aos gerentes. Para ele, as medidas de desempenho de curto prazo encorajam os executivos a se concentrar no agora, pois em geral são avaliados com base em medições anuais de custos, ganhos e crescimento. Como já vimos, os estudos de Mintzberg (1973), Kotter (1982) e Motta (1991) confirmam que o trabalho do gerente hoje é marcado pela brevidade, pela fragmentação e o imediatismo.

Ritmo e carga de trabalho. A palavra de ordem na administração durante as décadas de 1980 e 1990 é a reengenharia. Estima-se que no país onde se originou — EUA -, pode ter chegado a 39 milhões a "redução" de trabalhadores empregados durante o período de 1980 a 1995 (Sennett, 2000:57). Para os autores mais reconhecidos no assunto, como Hammer e Champy (1993), reengenharia pode ser entendida como uma redefinição de processos visando à máxima eficiência. Aos trabalhadores que sobrevivem ao processo de enxugamento, o que lhes resta é mais trabalho e um aumento do ritmo pelo qual ele é feito, além da queda de moral. Para Ruddle e outros (1998), um aspecto alarmante do enxugamento de escalões intermediários, relatado por alguns estudos, é uma queda do moral, o que poderia ser parcialmente explicado por uma maior insegurança na carreira.

Condenado a vencer. Do gerente, em regra, não se espera retrocesso, ou mesmo estagnação na carreira. A organização, seus pares e colaboradores (internos e externos) têm, em princípio, uma expectativa de crescimento dele na hierarquia, por ocupar um cargo visto pela maioria como uma conquista, por ser ele um premiado a ocupar uma posição, ou, em muitas situações, um “vencedor”. Pagès e colaboradores (1993:133), numa pesquisa feita numa grande multinacional, percebem com certa clareza esta expectativa de crescimento em relação ao gerente, como de diferentes formas o gerente sente-se pressionado a crescer e como ele mesmo incorpora este "fato": "(o gerente) tem o sentimento de estar preso, sugado, de não poder fazer 
outra coisa senão subir, de não poder mais parar, com risco de recuar. Ele não escolhe fazer carreira, realmente é levado a isto”.

\section{Síntese de abordagens do fenômeno workaholic}

Apesar desse fenômeno ainda não ter sido alvo de numerosos estudos, alguns trabalhos já foram produzidos, ensejando um início da análise científica que aponta para uma área de estudo promissora. A seguir, reportaremos sinteticamente um levantamento realizado sobre a produção até então disponível.

Quem primeiro abordou o fenômeno workaholic como um tema de estudo foi o psicólogo americano Wayne Oates, em 1968, num artigo intitulado “On being a 'workaholic'”, no qual relatava sua própria experiência e, ao se comparar a um alcoólatra, o autor afirmava ser também um viciado, mas em trabalho. Mais tarde, Oates (1971) definiu workaholism como um vício para trabalhar, compulsão ou a necessidade incontrolável para trabalhar incessantemente.

Dando continuidade ao trabalho iniciado por Oates, alguns autores abordaram o tema numa perspectiva psicanalítica (Fassel, 1990; Morrow, 1983; Killinger, 1991; Machlowitz, 1980; Schor, 1991). Killinger (1991) o faz descrevendo o workaholic como um indivíduo que, numa tentativa de ser aceito, respeitado e aprovado pelo outro, faz do trabalho um meio de alcançar tal aprovação e sucesso. Os trabalhos de Machlowitz (1980) e de Schor (1991) concentram-se na preocupante questão do aumento de casos.

A consideração de alguns aspectos organizacionais na abordagem do fenômeno - embora não focalizando tais aspectos com ênfase - pode ser observada, nos trabalhos de Machlowitz (1980) e de Scott e outros (1997). Curiosamente, neste último grupo de estudos, o fenômeno workaholic recebe uma conotação positiva, não sendo visto portanto como uma patologia.

Gostaríamos de destacar o estudo de Scott e colaboradores (1997), por nos parecer um pouco mais completo que os demais. Após fazerem um levantamento da literatura existente, os autores identificam três tipos de padrões de comportamento workaholic: compulsivo-dependente, perfeccionista e o orientado para realização. As características que compõem esses padrões são analisadas como variáveis contínuas, assim, os padrões não são mutuamente exclusivos e um workaholic pode ser uma combinação de qualquer dos dois ou de todos os três tipos.

O workaholic “compulsivo-dependente” é caracterizado pela compulsão para trabalhar ou pela dependência de trabalho, o indivíduo trabalha de forma excessiva ou irracional e mesmo reconhecendo o excesso ele não consegue se controlar ou reduzir a sua carga de trabalho. O padrão “perfeccionista” apresenta como principais características a forte necessidade de estar no controle, a forma 
rígida e inflexível de administrar, a busca agressiva de poder para dominar o ambiente e o trabalho, e a preocupação exacerbada com detalhes, regras e relatórios. Já o padrão denominado “orientado para realização”, manifesta alto desejo para mobilidade superior na carreira e alta motivação de realização, forte identidade com a carreira, habilidade para lidar com a demora de satisfação e disposição para esperar por recompensas; além disso, ele responde positivamente à competição, está disposto a avançar com esforço para atingir a excelência, e anseia por um cargo com mais responsabilidade e renda crescente. Uma outra contribuição dos autores é a síntese, realizada a partir do exame da literatura, dos elementos que consideram básicos na identificação de indivíduos com padrões de comportamento workaholic:

t tais indivíduos gastam uma grande parte de seu tempo em atividades de trabalho, dando demasiada importância para ele, abdicando de outros aspectos sociais família, amigos, lazer, entre outros;

t eles persistem em pensar freqüentemente em assuntos de trabalho, mesmo quando não estão efetivamente trabalhando;

eles trabalham muito além do que é razoavelmente esperado do cargo que ocupam, ou do que para atender suas necessidades econômicas básicas.

Os autores preferem interpretar o workaholism como o resultado de variáveis pessoais, embora considerem que variáveis situacionais podem constituir um fator importante no desenvolvimento e manifestação dos comportamen-tos analisados.

\section{Metodologia}

Nesta seção, descreveremos a metodologia utilizada, assim como apresentaremos um perfil dos gerentes consultados na pesquisa de campo.

Na categoria gerente, inserimos indivíduos que, como membros de organizações formais, ocupam posições de comando, tomam decisões importantes para os destinos da sua organização, e que concentram responsabilidades acumuladas em decorrência do cargo, desde o gerente operacional ao gerente executivo. Assim, a pesquisa de campo foi realizada com oito gerentes de empresas diferentes, portes e segmentos de mercado também diferentes, em quatro estados do país.

Os materiais que constituem o corpus desta investigação foram levantados em séries sistemáticas de entrevistas semi-estruturadas, que foram realizadas durante 0 período de novembro de 2002 a abril de 2003. Foram utilizados como fontes secundárias documentos internos contendo normas, regras, metas, missões, estraté- 
gias, objetivos das empresas desses gerentes, fazendo-se uma análise documental do material colhido. Por uma questão de preservação do anonimato dos entrevistados e das empresas, e para que assim os gerentes pudessem ter maior espontaneidade nas entrevistas, eles aqui estão denominados por códigos (São Paulo, Bahia 1...) de acordo com a região do entrevistado. A seguir, apresentaremos em breves linhas os sujeitos da pesquisa de campo e suas respectivas organizações. Após as apresentações, reportaremos a análise dos dados.

São Paulo tem 49 anos, é formado em engenharia elétrica, está na empresa desde 1991 e como sócio-proprietário desde 1996. A empresa de informática atua na área de consultoria, auditoria e terceirização de informática, auto-source, desenvolvimento e implantação de sistemas. A empresa tem um faturamento médio de R \$ 10 milhões/ano (estimativa de R \$ 15 milhões para 2004), conta com 130 funcionários e atende todo o território brasileiro com clientes mais concentrados nos estados de São Paulo, Pará, Bahia, Alagoas e no Distrito Federal.

Bahia 1 tem 47 anos, é engenheiro com mestrado em administração de empresas, atuou como diretor durante 18 anos, sendo seu primeiro cargo em diretoria aos 28 anos. Trabalhou durante nove anos como diretor numa empresa no Pólo Petroquímico de Camaçari, cujo faturamento anual na década de 1980 era da ordem de US\$ 130 milhões, com 3.500 empregados. Durante esse período, a revista Exame publicou uma reportagem sobre workaholic em que Bahia 1 foi entrevistado. Depois, na década de 1990, assumiu por oito anos a diretoria de outra empresa petroquímica que tinha faturamento de US\$ 30 milhões, passando para US\$ 150 milhões. Hoje atua como consultor.

Bahia 2 aposentou-se como adjunto financeiro numa multinacional brasileira, depois de uma carreira de 30 anos. No momento, está no comando da área financeira de uma empresa petroquímica. É formado em administração de empresas e em contabilidade. A empresa tem 240 empregados e investe muito em tecnologia, o que lhe dá uma certa flexibilidade de produção sendo um diferencial no seu mercado, e alguns dos seus produtos somente ela produz no Brasil.

Feira também é diretor financeiro. Ele tem 45 anos, é graduado em contabilidade e faz mestrado em mercado de capitais e finanças, sendo também professor numa universidade local. A empresa opera mais no Norte-Nordeste, onde fabrica, comercializa, importa, exporta e representa produtos de ferro e aço (laminação, trefilação, recozimento, galvanização de metais); ela tem 210 funcionários diretos e 1.200 indiretos. Duplicou sua produção entre os anos de 1999 e 2002, e em alguns produtos tem domínio amplo de mercado. Faturamento acima de $\mathrm{R} \$ 100$ milhões.

Curitiba 1 tem 36 anos, é formado em engenharia da computação e trabalha numa empresa do ramo de telecomunicações que atua em grande parte do país. Ocupa um cargo de gerência. Durante um período de 10 meses ficou afastado da empre- 
sa por motivo de doença diagnosticada como decorrente do estresse causado pelo trabalho que realizava na época.

Curitiba 2 também trabalha na mesma empresa de telecomunicações citada, onde é gerente de produto. Tem 31 anos, fez quatro anos de engenharia eletrônica, parou, se decepcionou com o curso, foi fazer psicologia, cursou durante dois anos. Por estar constituindo família, achou melhor voltar a estudar engenharia, abandonando a psicologia por acreditar que seria mais difícil para se manter trabalhando nessa área.

Rio 1 ocupa uma gerência na área financeira, tem 37 anos e é formado em administração com especialização em finanças. A empresa atual é seu segundo emprego, funcionário de carreira, tem 13 anos de casa, sob seu comando tem seis indivíduos. A empresa inicialmente era uma multinacional; foi desmembrada em empresas menores, tem 100 anos de Brasil, possui 320 funcionários. Para alguns dos seus produtos somente esta empresa tem autorização da Confederação Nacional da Indústria para produzir e comercializar, para outros produtos praticamente não tem concorrente, detendo $80 \%$ do mercado brasileiro; fabrica tubos de canalização para saneamento básico e uma série de outros acessórios para rodovias.

Rio 2 é gerente de logística numa empresa de grande porte, onde tem sob seu comando 70 funcionários e 800 terceirizados. A empresa trabalha com bens de consumo, possui 17 mil trabalhadores diretos e 15 mil terceirizados, é líder no mercado nacional, com espaço de mercado na América do Sul, alguns países na América Central e Europa, e exporta seu produto para outras regiões do mundo. Rio 2 tem 31 anos e é formado em engenharia eletrônica, no momento da pesquisa estava fazendo um MBA em São Paulo.

\section{Análise dos dados}

Primeiramente, apresentaremos uma síntese do conjunto de dados coletados referentes aos elementos de identificação do fenômeno workaholic, conforme definidos anteriormente. Na segunda parte desta seção, reportaremos a análise dos dados relativos às exigências organizacionais.

\section{Elementos de identificação do fenômeno workaholic}

Gastar uma grande parte de seu tempo em atividade de trabalho, dando-lhe demasiada importância e abdicando de outros aspectos sociais. Todos os entrevistados afirmaram trabalhar freqüentemente em torno de 12 horas por dia. Obtivemos declarações como: "Para o gerente, não tem limite, não tem limite de horário" (Fei- 
ra); "Para você ter uma idéia, eu trabalhava em média umas 16 horas por dia (...), eu trabalhava, trabalhava bastante, naquele momento eu me dedicava muito, a minha vida era em função do meu trabalho” (Curitiba 1); “Hoje me sinto vivendo para trabalhar, amanhã [domingo] eu vou trabalhar e eu ainda não tive coragem de dizer para minha mulher, não tive coragem de dizer para minha família” (São Paulo). Com relação às férias, encontramos gerentes que há quatro anos não tiram férias, outros dois tiveram três férias nos últimos cinco anos, um outro no período de 10 anos apenas três vezes, ainda assim de 20 dias. Em determinada situação, afastar-se da empresa por motivo de férias parece causar mais tensão do que a pressão normal do cargo: "Sair de férias quando você tem aquela percepção de que as coisas que deixou esperando [assuntos pendentes] continuam lá te esperando, te dá um desespero!” (São Paulo).

Pensar persistente e freqüentemente em trabalho, mesmo quando não está no trabalho. A preocupação com o trabalho é uma constante na vida desses gerentes. Mesmo quando não estão trabalhando, a preocupação com os assuntos relacionados ao trabalho os acompanha. Na sua maioria, eles pensam em trabalho quando estão em casa. Apenas um relatou que consegue se desligar dos problemas do trabalho quando não está trabalhando. Fizemos a seguinte pergunta: “em porcentagem, o quanto você tem que dedicar de atenção a essa empresa por dia?”; ao que responderam ser acima de $80 \%$ de suas atenções voltadas para questões de trabalho, sendo registrado que um deles respondeu ser entre 30\% e 40\%. Obtivemos algumas falas tais como: "Penso bastante. Eu sempre me pego pensando em trabalho, é impressionante (...) às vezes também o problema acompanha, você sai do trabalho com o problema em aberto e aí ele acompanha, eu procuro resolver tudo para que isso não aconteça, mas acontece sempre" (Rio 2); "Se você passa 12 horas dentro da empresa, e você está submetido a isso aí, quando você vem pra casa você não desliga, e é isso aí que está acabando com os casamentos do pessoal lá, não desliga mesmo” (Curitiba 2).

Trabalhar muito além do que é razoavelmente esperado do cargo que ocupa, ou do que é preciso para atender suas necessidades econômicas básicas. Todos esses gerentes lidam com a questão da ambição demonstrando uma certa tranqüilidade. Conversando sobre esse tema, todos se declararam ambiciosos, algumas vezes a palavra veio seguida de um outro termo (voluntariedade, motivação) ou observações como: ser ambicioso é a força motriz da ação humana, ou um indivíduo sem ambição é um indivíduo sem futuro. Algumas afirmações: “Todos eles [os executivos] estão sujeitos a pressões terríveis, todos eles abrem mão de muitas coisas do lado pessoal para poder ter um desempenho profissional, um progresso, uma prosperidade que eu contesto muito” (São Paulo); “Temos que fazer um pouco mais do que aquilo que as pessoas esperam de você, respiro metas e busco o tempo inteiro a superação delas” (Rio 2). 
Mesmo reconhecendo o excesso de trabalho não consegue controlar ou reduzir. Os gerentes entrevistados reconhecem e se queixam da excessiva carga de trabalho, porém todos afirmaram não ser possível reduzi-la sem que isso venha a prejudicar sua carreira. O depoimento desse entrevistado que sofreu sérios problemas de saúde devido ao excesso de trabalho é contundente: “Às vezes acontece o excesso, você gostar de mais de uma coisa então você faz o tempo inteiro e fica naquele vício de resolver, um problema por exemplo, e isso aí te desgasta de várias maneiras (...) Eu gosto de resolver problemas, de achar a solução, eu trabalho para isso, eu trabalho bastante. Ele [o trabalho] está legal quando você percebe que já é fim de semana de novo (...) Naquele momento [antes de ficar doente] eu me dedicava muito, a minha vida era em função do meu trabalho” (Curitiba 1).

Ser perfeccionista, apresentando necessidade de estar no controle e domínio do ambiente. Seis dos oitos gerentes declaram-se perfeccionistas, atribuindo o controle como questão-chave para o sucesso. As declarações o atestam: "Fracasso e sucesso se resumem em resultado, se for o esperado é sucesso (...) não acredito muito em fracasso, acredito em falta de controle da situação (...) O controle está diretamente ligado ao domínio que você tem do que faz e das pessoas que estão em volta de você, do ambiente que te envolve, é decisivo para o teu sucesso (Curitiba 1); “Se eu tiver todo o meu sistema sob controle, deveria trabalhar menos, mas acontece que, como eu sou um eterno insatisfeito, por mais que melhore e melhore, ainda pode melhorar mais” (Bahia 2).

Responder positivamente à competição. Os entrevistados declararam como uma de suas principais características ou qualidades o espírito competitivo. Com exceção de São Paulo, que declarou ser competitivo por força do cargo e das regras do jogo do mercado, todos os outros se declararam competitivos sem quaisquer ressalvas. Algumas reflexões que registramos: “O ambiente de trabalho sempre é competitivo, pode ser demais ou pode ser médio, mas sempre competitivo. Você vive numa pirâmide, na qual as pessoas querem subir e não tem espaço para todos" (Bahia 1); "Fui treinado para ser competitivo" (Bahia 2); "Sou bastante competitivo. Eu me sinto num mundo extremamente competitivo, sou incentivado pela competição, e acho que é fundamental para o sucesso profissional” (Rio 2).

\section{Exigências organizacionais}

Aceitação do risco. A maioria das empresas dos gerentes pesquisados trabalha com gestão por objetivos, portanto, existe o risco do alcance ou não das metas. A complexidade do cenário atual (instabilidade, ambigüidade, imprevisibilidade, rápidas e constantes mudanças), no qual o passado não é útil como guia (Kliksberg, 1993), também implica, assim como as metas, risco para esses profissionais, uma vez que 
seus cargos clamam por uma infinidade de tomadas de decisão, e para se manter nessa posição de gerência espera-se que, na sua maioria, essas decisões sejam acertadas. Ser testado ou pelo menos ter a sensação de estar sendo testado a todo o momento é uma situação detectada nos depoimentos dos gerentes: "Eu prefiro entender que meu contrato de trabalho termina todo dia, acho uma boa maneira de você abordar as coisas desse jeito” (Bahia 2); “A todo o momento sou testado aqui dentro" (Feira); "O risco faz parte, você tem que colocar em mente que tem que fazer sempre o melhor” (Rio 1). Alguns mecanismos adotados por esses gerentes para administrar a variável risco foram anotados, como: ter cuidado dobrado com a tarefa de organizar; ser político e investir na rede de relacionamentos, tanto interna quanto externa; conhecer bem o que faz e o mercado; manter-se informado. Porém o que mais se repete nos comentários deles é ter controle, pois, como afirma Curitiba 1: "Sem controle você está arriscado a 'rodar', pode ser mandado embora sem saber o porquê, não consegue nem anotar a placa do caminhão que te atropelou”. Uma tal importância atribuída ao controle para redução do risco remete-nos à rubrica analisada anteriormente: o perfeccionismo - um dos elementos de identificação do fenômeno workaholic.

Complexidade. Não é mais possível para o gerente moderno conhecer todo o trabalho do seu subordinado como acontecia com o gerente de sucesso no passado. Atualmente parece ser humanamente impossível cobrir o conhecimento, as informações técnicas ou conceituais da sua área (Kliksberg, 1993). A amplitude de visão e a constância do novo que acrescenta ou substitui totalmente o que se está usando (ou praticando) no presente fazem parte do seu dia-a-dia. Nas entrevistas, os gerentes falaram sobre a freqüência de coisas novas e as conseqüências nas suas respectivas áreas: "Saber lidar com a inovação é prerrequisito, se você não souber lidar, você não vai fazer nada, porque as coisas mudam muito rápido” (Curitiba 1); “Tem que monitorar a conjuntura o tempo inteiro, claro, isso traz um certo estresse, mas é necessário. Comandar uma grande empresa é como estar manobrando um grande navio, por isso sua preocupação de visualizar antes, porque a margem de manobra é mais difícil, mais lenta, isso traz um certo nervosismo” (Bahia 1). Esse monitoramento permanente da conjuntura, em muitas circunstâncias, pode se relacionar com a seguinte característica discutida acima: persistente e freqüentemente pensa em trabalho, mesmo quando não está no trabalho. Continuando: "Eu trabalho há 25 anos na área, no início as coisas eram muito simples, hoje tudo é interligado, uma malha de ligação enorme, muito complexo, me assusta. O grande desafio que enfrentamos na nossa área é que cada vez mais as soluções são mais complexas, mais integradas a tudo” (São Paulo). Questionado se hoje ele trabalha mais do que no passado, a resposta é sim, “muito mais do que antes, absurdamente”. As evidências acentuam que seja pela complexidade ou pelo que é exigido ao gerente em decorrência do ritmo e carga de trabalho (como será analisado posteriormente), a sua carga de trabalho au- 
mentou. A complexidade analisada estabelece relações ou implicações com outras exigências: o fator risco, a flexibilidade e o curto prazo, como veremos.

Flexibilidade. Ser flexível no moderno léxico administrativo significa ser adaptável a circunstâncias variáveis. As características do cenário atual das empresas (turbulência, instabilidade, incerteza, elevada competição) têm relações com tais circunstâncias. A flexibilidade apresenta-se como uma das principais competências do gerente moderno. Um estudo com 3 mil executivos americanos concluiu que a qualidade isolada mais importante daqueles que lidavam bem com o sucesso, e eram capazes de mantê-lo, era a habilidade de aceitar a mudança (Webber, 1997). Um sistema de produção flexível, implantado para responder à volatilidade do consumidor, ou por iniciativa estratégica das próprias empresas, tem reflexo nas exigências ao gerente. Mudar, sempre mudar, apresenta-se como palavra de ordem na vida profissional dos gerentes entrevistados. Registramos nesses depoimentos a importância atribuída por eles à capacidade de produção flexível para explicar o sucesso de suas respectivas empresas; nesse contexto, o que mais gostaríamos de ressaltar são as suas declarações a respeito de como eles devem se comportar perante a flexibilidade organizacional: “O profissional que não cabe na empresa é aquele cara que não é flexível. Se ele mantém sempre a posição dele, ele não consegue sobreviver aqui dentro... Tem uma série de coisas que acontecem e que você precisa negociar” (Rio 1); “A primeira coisa é essa adaptação, tem que ser muito versátil, você não pode ser uma pessoa muito especialista, não pode não ter flexibilidade, versatilidade para estar se adequando a mudanças. Porque é muito dinâmico, é superdinâmico” (Rio 2).

Curto prazo. As exigências organizacionais analisadas até aqui estabelecem relações estreitas com o curto prazo. O fator risco constantemente presente e a instabilidade - seja por uma estratégia das empresas para uma maior produtividade, seja pela competição existente - não permitem planos futuros de longo prazo ao gerente. E as intermináveis mudanças com as quais ele se depara na sua profissão podem significar que a sua flexibilidade não seja suficiente para se adaptar a tais mudanças. Todos esses fatores fazem do curto prazo mais um elemento das exigências organizacionais ao gerente. O estar concentrado no presente acarreta sérias implicações: frouxos laços de relacionamentos, frágeis vínculos com os colegas e com a empresa, viver o futuro imediato, tudo isso acarreta uma "corrosão do caráter" (Sennett, 2000), entre outras conseqüências. Equipes temporárias para realização de projetos, situações dinâmicas e flexíveis anotadas nas empresas de São Paulo, Rio 2, Curitiba 1 e Curitiba 2 são fatores que não permitem uma integração e relações duradouras com os demais trabalhadores da empresa. Os gerentes não podem fazer planos de longo prazo tendo por base o seu emprego, pois em alguns casos a continuidade do seu contrato de trabalho está relacionada ao fechamento anual das suas metas. Metas alcançadas, isso significa que seu contrato pode ser renovado por 
mais um ano, se não acontecer do seu departamento ser desativado, conforme alerta Curitiba 2: "Para os outros gerentes é ainda pior, não chega a nem um ano, porque ele pode estar no departamento que não é essencial para a empresa (...) Às vezes o cara é bom, mas o departamento dele foi desmontado, o cara roda”. Em todas as entrevistas, foi revelado que a atenção do gerente está voltada só para o curto prazo, nunca mais que três anos.

Ritmo e carga de trabalho. Um ritmo acelerado de trabalhar para dar conta das demandas diárias do cargo, esta é uma constatação quase que geral dos entrevistados. “Agendas lotadas”, “muito por fazer”, “quadro de empregados enxuto”, “melhor se o dia tivesse 48 horas", "trabalhar de forma alucinante”, "tem que ter pique”, entre outras colocações estão diretamente relacionadas a vários dos elementos de identificação do comportamento workaholic, bem como à exigência de flexibilidade, todos já analisados. Observa-se que o trabalho desses gerentes, além de ser caracterizado por longas jornadas (primeiro item do workaholism), é realizado de forma intensa, “pesada” (termo usado por Bahia 1, Rio 2 e Curitiba 2), ou seja, temse muito trabalho para realizar, muitos assuntos para resolver e decisões a serem tomadas durante a jornada e extrajornada de trabalho. O aumento do volume de trabalho administrativo tem sido registrado em algumas pesquisas (Webber, 1997; Ruddle et al., 1998). Para Igor Ansoff e outros (1981), “A sobrecarga física já é evidente em muitos níveis gerenciais”. Segundo Bahia 1, “Tive uma carga de trabalho enorme, chegava muito cedo e saía muito tarde, tive até uma reportagem da revista Exame. Quando foram procurar um workaholic aqui na Bahia para essa reportagem nacional me procuraram”. Um outro aspecto que tem implicações com o ritmo e carga de trabalho diz respeito às empresas modernas trabalharem com seu quadro funcional bastante enxuto. Trabalhar com uma filosofia organizacional que busca "fazer mais com menos” parece ser uma obsessão das empresas dos entrevistados e as implicações possíveis têm sido a redução da mão-de-obra, tanto gerencial quanto operacional. Seguem algumas declarações com relação a esse assunto: “Ele [o gerente] está sendo exigido pra caramba, o pessoal trabalha com um time enxuto mesmo subdimensionado — , tem até coisa operacional pra resolver (...) o regime da sobrecarga é o regime, é o normal, a regra é a sobrecarga” (Curitiba 2); “A empresa tinha 450 funcionários, ficou com 65, faturava US\$ 30 milhões e passou para US\$ 150 milhões” (Bahia 1). O que as empresas podem estar sinalizando nesse processo de “seleção natural” dos trabalhadores é que aquele que vai continuar no mercado é o trabalhador que suporta este aumento da carga de trabalho e que tem uma velocidade maior de fazer as coisas.

Condenado a vencer. Ser ou estar gerente significa, na quase totalidade dos casos, uma conquista, uma vitória, excluindo os casos em que se alcança a gerência por uma "herança familiar”. Os oito gerentes entrevistados têm esse entendimento, embora, em um caso específico, tenhamos que fazer uma ressalva. No momento da 
pesquisa, o gerente São Paulo questionava suas conquistas profissionais: "Eu atingi o sucesso profissional com um esforço fora do normal que acabou comprometendo a minha qualidade de vida, então é uma ilusão. O sucesso que eu tive foi a um custo completamente inadmissível, isso invalida o meu sucesso” (São Paulo). Não obstante, o sentimento de uma forma ou de outra é generalizado como o de uma conquista. As expectativas da quase totalidade desses gerentes são de mais conquistas. Tais expectativas não parecem ser só deles, mas também da organização. Seguem algumas declarações: “O que a empresa espera dos indivíduos? Compromisso, atitude adequada, necessidade de crescimento” (Bahia 1); “A principal característica para um gerente desempenhar um bom papel nesta empresa é buscar sempre o crescimento” (São Paulo); “É uma exigência administrativa, a empresa quer alguém que queira almejar além daquilo que está ao redor dela, que queira evoluir técnica e profissionalmente, tem que querer estar sempre evoluindo” (Rio 1); “A empresa quer pessoas de sucesso" (Rio 1). Isso pode conduzir certos indivíduos a uma espécie de fixação: "Eternamente insatisfeito, se indignar a cada momento achando que o resultado poderia ser ainda melhor (...) é um pouco daquela indignação que eu estava falando: estou indignado, preciso vender mais, tenho que ganhar produtividade, tenho que me superar a cada momento" (Rio 1); "Eu quero crescer e crescer, quero ser diretor dessa companhia, quero crescer profissionalmente, pessoalmente e financeiramente, essas são as minhas ambições” (Rio 1). A eterna insatisfação, a busca exacerbada do sucesso são manifestações que podem ser relacionadas com pelo menos dois elementos do workaholism: o perfeccionismo e as longas jornadas de trabalho.

\section{Conclusões}

Com este artigo, promovemos uma reflexão sobre alguns aspectos cruciais do mundo do trabalho atual, ao examinar as possíveis relações entre as exigências ao gerente moderno e o chamado fenômeno workaholic. Ao fazê-lo, ressaltamos algumas implicações na vida dos gerentes, colocando as conseqüências dessas práticas administrativas como um fenômeno social que merece atenção e mais estudos. Todos os gerentes entrevistados tiveram implicações, em menor (esgotamento físico e mental, estresse, enxaquecas) ou maior grau (enfarto, úlcera gástrica, distúrbio do sistema imunológico) como decorrência das preocupações e do ritmo impostos pelo trabalho. Alguns tiveram incorporado no seu modus vivendi comportamentos e atitudes que praticamente os excluem dos outros segmentos sociais ou familiares, demonstrando, inclusive, o não-saber como viver nos demais espaços sociais (três gerentes declararam ter dificuldades para preencher seu tempo livre em atividades não relacionadas a trabalho). 
O gerente está sujeito a situações de complexidade, de ter que lidar com a flexibilidade, com o curto prazo, com o fator risco, de ter um ritmo e uma pesada carga de trabalho, e onde se espera dele que seja um vencedor. Apresentamos evidências dessas situações como um reflexo do contexto estudado e descrito neste artigo. O modelo de desenvolvimento fordista, ao apresentar sinais de esgotamento (Lipietz, 1991), não encontra as respostas para as suas freqüentes crises estruturais e acentua as exigências organizacionais que se faz a quem se encontra numa posiçãochave num processo produtivo. A lógica do descartável, típica característica do modelo de consumo em massa, extrapola o âmbito dos bens e serviços e invade o ambiente dos indivíduos nas organizações: “A empresa me paga bem, mas me cobra muito, temos uma pilha de currículos cadastrados que dá três vezes o nosso quadro de funcionários, tem fila para o meu lugar, trocar e colocar outro é rapidinho” ( $\mathrm{Cu}$ ritiba 2). Como não se sujeitar a essas exigências, como negociar ou rejeitar algo que vem determinado da direção das empresas ou mesmo do mercado? Conclui-se que para esses gerentes o fator risco sempre os estará acompanhando.

Alguns dos mecanismos para gerenciar o risco que foram detectados nas entrevistas, como redobrar a atenção e aumentar o controle, têm implicação direta com o fenômeno workaholic (perfeccionismo, necessidade de estar no controle e domínio do ambiente). Dominar, compreender, monitorar, controlar e outras expressões que denotam uma tentativa de gerenciar na complexidade foram manifestadas pelos entrevistados. No entanto, essa complexidade, marcada pela irregularidade dos acontecimentos, fragmentação do trabalho, novidades constantes, variedade dos afazeres, diversidade de especialistas sob seu comando, clama por respostas dos gerentes que em muito se aproximam daquelas identificadas no comportamento do workaholism, tais como a do tempo excessivo no trabalho, de pensar em trabalho mesmo fora dele, de trabalhar além do razoável, de reconhecer o excesso de trabalho mas não conseguir reduzi-lo e do perfeccionismo.

A adaptabilidade que se deseja do gerente (o ser flexível) impõe-se como uma exigência organizacional, como uma característica decisiva para se ter sucesso no cargo. Essa flexibilidade estabelece uma clara relação com o fator risco. A flexibilidade necessária para as rápidas mudanças de rumo das escolhas e decisões administrativas remete o gerente ao desconhecido, portanto, a uma situação de risco. A aceitação do risco, conforme foi visto, tem conexões com determinados elementos do comportamento do workaholic.

As empresas, em nome da competitividade, têm no seu arrazoado a redução de custos que em muitas situações acaba sendo sinônimo de redução de mão-deobra. Nos diferentes mercados das empresas dos gerentes pesquisados, todos registram queda no número de empregados e elas mesmas seguem essa tendência, com exceção apenas de uma que é nova e já nasceu enxuta: "Para você ter uma idéia, a minha área aqui tem 24 pessoas, o concorrente trabalha com 50” (Curitiba 1). Esse 
processo tem como conseqüência direta para os gerentes o aumento da carga de trabalho, implicando, na maioria dos casos, terem que aumentar seu ritmo de trabalho e sua jornada para atender à nova realidade. Conclui-se que essa situação pode estabelecer correspondência com alguns elementos do workaholism (longas jornadas de trabalho, trabalhar além do razoável e não controlar o excesso).

O estar condenado a vencer como uma situação vivida por todos os gerentes estudados estabelece uma relação direta, ao menos, com os seguintes elementos do fenômeno workaholic: responder positivamente à competição e o perfeccionismo.

Assim, nesta pesquisa encontramos evidências de que as exigências organizacionais aos gerentes têm relação com a ocorrência do fenômeno workaholic na gestão das empresas contemporâneas. Cremos estar contribuindo para esse novo e necessário campo de estudos, descortinando nele o enfoque organizacional, o qual pode se colocar em posição de complementaridade aos estudos que vêm sendo realizados com enfoques na psicologia e na psicanálise. Acreditamos que a melhoria da compreensão do fenômeno workaholic implica também considerar na sua análise pontos de vista históricos, econômicos, sociais e organizacionais; a ocorrência e mesmo o incremento desse fenômeno na atualidade pode não se dever somente à predisposição psíquica de certos indivíduos. O exame do contexto ampliado e do locus (nesse caso, as organizações) onde essa grave patologia se manifesta pode lançar novas luzes sobre ela e nos ajudar a labutar em prol de um mundo do trabalho mais humanizado.

\section{Referências bibliográficas}

ANSOFF, Igor et al. Do planejamento estratégico à administração estratégica. São Paulo: Atlas, 1981.

BARROS, Betania. Manual de gestão de pessoas e equipes. São Paulo: Gente, 2002.

BECK, Ulrich. La sociedad del riesgo: hacia una nueva modernidade. Barcelona: Paidós, 1998.

EXAME. Procura-se atleta corporativo. Exame, São Paulo, ed. 759, ano 36, n. 3, p. 32-45, 6 fev. 2002.

FASSEL, D. Working ourselves to death: the high cost of workaholism, the rewards of recovery. San Francisco: Harper Collins, 1990.

GOLDBERG, Philip. A saúde dos executivos: como identificar sinais de perigo para a saúde e levar a melhor contra o estresse. Rio de Janeiro: Zahar, 1980.

GRUPO CATHO. Empresários brasileiros passam muito tempo trabalhando. In: Catho on-line, carreira \& sucesso, n. 182. Disponível em: <www.catho.com.br>. Acesso em: 3 jun. 2003.

HAMMER, M.; CHAMPY, J. Reengineering the corporation. New York: Harper Collins, 1993. 
KILLINGER, B. Workaholic: the respectable addicts. New York: Simon \& Schuster, 1991.

KLIKSBERG, B. A gerência no final do século XX. Revista de Administração Pública, v. 27, n. 2, p. 183-201, abr.jun. 1993.

KOTTER, J. The general managers. New York: Free Press, 1982.

LIPIETZ, A. Audácia: uma alternativa para o século 21. São Paulo: Nobel, 1991.

LIRA, C. Mundo globalizado, trabalhador estressado. Voz do Paraná, Cascavel, 9 jul. 2003.

MACHLOWITZ, M. Workaholics: living with them, working with them. Boston: Addison-Wesley, 1980.

MCCLELLAND, D. A sociedade competitiva: realização e progresso social. Rio de Janeiro: Expressão, 1972.

. O poder é o grande motivador. São Paulo: Nova Cultural, 1987.

MINTZBERG, H. The nature of managerial work. New York: Harper and Row, 1973.

MORROW, P. Concept redundancy in organizational research: the case of work commitment. Academy of Management Review, v. 8, n. 3, p. 486-500, July 1983.

MOTTA, P. Gestão contemporânea: a ciência e a arte de ser dirigente. Rio de Janeiro: Record, 1991.

OATES, W. Confessions of a workaholic: the facts about work addiction. New York: World Publishing, 1971.

PAGÈS, M. et al. O poder das organizações. São Paulo: Atlas, 1993.

RUDDLE, K. et al. Do enxugamento à revitalização. Gazeta Mercantil, n. 6, ago. 1998. (Global Business.)

SCHOR, J. The overworked American. New York: Basic Books, 1991.

SCOTT, K. et al. An exploration of meaning and consequences of workaholism. Human Relations, v. 50, n. 3, 1997.

SENNETT, R. A corrosão do caráter: conseqüências pessoais do trabalho no novo capitalismo. São Paulo: Record, 2000.

VALDEJÃO, R. Carreira executiva: jornada é de dez horas no mínimo. Disponível em: <www.agr.feis.unesp.br/fsp>. Acesso em: 10 jul. 2003.

WEBBER, R. Imperativos modernos. Gazeta Mercantil, v. 1, ago. 1997. (Management.) 